\title{
INTRODUCERE ÎN SUBIECTUL TEZEI. CONSIDERAȚII PRELIMINARE*
}

Horea NAȘCU ${ }^{* *}$

\section{Introduction to Thesis Topic. Premilinary Considerations}

\begin{abstract}
The advent of the alphabet brings an end to the monopoly the ruling class had on knowledge for ages. The continuous improvement of the ensuing writing tools spawns into an overwhelming increase in the number of authors. Books today are sold in ever larger quantities; that, however, does not mean that books are also read. A researcher who chooses to deal with works which are so complex and well written, that they basically make the critical endeavour nearly useless, finds himself preyed upon by the fear of damaging that which he cherishes most in the selected work and author. The critical text, if completed appropriately, functions as an appendix to the work which occasions it; its primary purpose is to signal out and promote.
\end{abstract}

Keywords: instrument, reading, information, text, discourse.

Moto: Cerneala curge râuri. (Anonim)

Paul Coelho, aclamatul autor al unor romane logoreice construite în jurul câte unei idei pe care un scriitor talentat ar putea clădi o povestire bună, vorbește, în Al cincilea munte $(1996)^{1}$, despre efectele inventării scrisului așa cum îl știm și îl practicăm și astăzi. Accesul la text însemna putere, universalizarea acestui acces însemna disiparea puterii și, în consecinţă, foarte probabil, pierderea statutului și a privilegiilor claselor dominatoare: conducătorii laici și Biserica. Într-adevăr, nimic nu avea să mai fie la fel: odată deprins alfabetul, drumul către cunoaștere se deschidea absolut oricui. În ochii Preotului autorului brazilian, cuvântul, arma aparent cea mai îngrozitoare care fusese inventată vreodată, aducea după sine, prin vulgarizare, sfârşitul civilizației ${ }^{2}$. De atunci încoace, omul s-a străduit să facă învățarea și utilizarea noului, mult mai eficientului sistem de scriere cât mai facile; nu în ultimul rând, s-au depus eforturi necontenite pentru crearea unor instrumente de scris din ce în ce mai performante. Pana, astfel, s-a

\footnotetext{
* Fragment dintr-o lucrare mai amplă, în curs de editare.

*** Lecturer PhD, Technical University of Cluj-Napoca, Faculty of Letters, Baia Mare, 76

Victoriei Street, Baia Mare (horea.nascu@cunbm.utcluj.ro).

${ }^{1}$ Paul Coelho, Al cincilea munte, traducere din portugheză de Carmen Vasilescu, București, Humanits, 2001.

${ }^{2}$ Cf. Paul Coelho, op. cit., p. 51.
} 
transformat curând în stilou ${ }^{3}$ iar acesta, în cele din urmă, după succesive perfecționări, aducându-l aproape în teritoriul operei de artă, în ceva și mai simplu: popularul, trivialul pix ${ }^{4}$. Iar între timp, de la instrumentul extrem de uşor manevrabil s-a trecut la dispozitive menite să facă multiplicarea textului la fel de banală ca potcovirea cailor sau coacerea pâinii. Tiparul ${ }^{5}$ a răspândit textul în toate colțurile lumii în exemplare, dintr-o dată, chiar în exces, umplând rafturile bibliotecilor publice mari și mici, dar și polițele din casele împătimiților de lectură - nenumărate volume, în consecință, rămânând adeseori neperturbate în librării. Iar pentru că, dintr-un motiv sau altul, din ce în ce mai multă lume părea să dorească să scrie, omului i s-a dat tiparnița personală: miraculoasa mașină de scris ${ }^{6}$ - care, la rîndul său, avea să fie complet ridiculizată și, după încă puțin timp, scoasă din uz de către computerul personal și imprimanta atașată acestuia?.

Profuziunea rezultată nu avea cum să fie pe placul acelor autori, infimi ca număr, pentru care scrisul este nu doar vocație, ci însăși rațiunea de a fi. Luptându-se, oricum, cu o tradiţie a excesului, în care cuvântul este aruncat pe pagină fără a fi întotdeauna nici necesar, nici măcar adecvat într-o măsură cât de cât satisfăcătoare, autori emblematici precum Eugen Ionescu ${ }^{8}$

\footnotetext{
${ }^{3}$ Cea mai timpurie mențiune a unui stilou este înregistrată în anul 973; vezi „Fountain Pen - History of Fountain Pens", History of Pencils: Pen and Pencils History, HistoryOfPencils.com, 2019, accesat la 8 decembrie 2019. Primul patent pentru un stilou a fost acordat unui român, Petrache Poenaru, în anul 1827; cf. Krishnan Unni, „,Fountain Pen: Science and History", Amrita Vishwa Vidyapeetham, amrita.edu, 22 octombrie 2018, accesat la 8 decembrie 2019.

${ }^{4} 1888$ este anul în care a fost patentat primul pix; cf. „Ballpoint Pen History - Who Invented Ballpoint Pen?" History of Pencils: Pen and Pencils History, HistoryOfPencils.com, 2019, accesat la 8 decembrie 2019.

${ }^{5}$ Cel mai vechi text tipărit este considerat The Diamond Sutra, datând din anul 868; tot în China găsim prima presă de tipar, datând din secolul al XI-lea, în vreme ce prima presă de tipar mecanică, faimoasa presă a lui Johannes Gutenberg, apare în Europa abia pe la jumătatea secolului al XV-lea; cf. History.com Editors, „Printing Press”, HISTORY, A\&E Television Networks, 7 mai 2018, actualizat la 10 octombrie 2019, accesat la 8 decembrie 2019.

${ }^{6}$ În vreme ce secolul al XIX-lea înregistrează diferite încercări de a crea o mașină de scris, prima mașină practică este cea patentată de Christopher Latham Sholes în anul 1868; cf. The Editors of Encyclopaedia Britannica, „Typewriter”, Encyclopcedia Britannica, Encyclopædia Britannica, inc., 13 februarie 2018, revizuit și adus la zi de Robert Lewis, accesat la 8 decembrie 2019.

${ }^{7}$ Primul computer personal ar data din 1975; cf. Computer Hope, "When was the first computer invented?" Computer Hope: History Q\&A, Computer Hope, 2 august 2019, accesat la 8 decembrie 2019.

8 Eugen Ionescu, 1909 - 1994; cf. Martin Bendig, „Biography”, Eugène Ionesco, ionesco.de, 2019, accesat la 27 noiembrie 2019.
} 
sau Samuel Beckett ${ }^{9}$ dispar, ca entități fizice, cam pe când ușurința de a lovi butoanele de plastic ieftin ale tastaturii începe să se traducă în explozii de maculatură care fie nu este citită de nimeni, fie alimentează intelectul firav al consumatorului de orice, neselectiv și indolent, suficient sieși.

În cuvintele controversatului Steve Jobs ${ }^{10}$, ,nu contează cât de bun sau rău este produsul, realitatea este că lumea nu mai citește"11 [tr.n.]. Dacă unii, înarmați cu alte statistici decât cele pe care Jobs și-a construit afirmația, susțin contrariul, acest fapt se poate datora interpretării reci, fără nuanțare a cifrelor. Se publică volume inumerabile iar acestea se cumpără din librării sau se împrumută din biblioteci, însă de aici nu rezultă implicit că omul întâiului deceniu al mileniului al III-lea utilizează cartea conform instrucțiunilor și menirii sale ${ }^{12}$. Un nivel tot mai scăzut al cunoștințelor generale, universal constatat și deplâns, dar, este adevărat, mai dificil de cuantificat decât cifrele seci raportate de către editori, librari și bibliotecari, pare să indice o schimbare fundamentală în registrul opțiunilor pentru petrecerea timpului liber, trecerea făcându-se în ritm accelerat dinspre lectură spre activităţi care fie nu implică participarea cerebrală intensă, fie denotă preferința pentru modalități mai rapide de acumulare a informațiilor.

A scrie, în aceste condiții, despre opera unor autori care fie au disprețuit încercările altora - confrați, critici $^{13}$, cercetători ${ }^{14}$ etc. - de a

9 Samuel Beckett, 1906 - 1989; cf. Benjamin Strong, „Samuel Beckett: A Short Biography", samuel beckett society: Biography, The Samuel Beckett Society, accesat la 27 noiembrie 2019.

${ }^{10}$ Steve Jobs, 1955 - 2011, cofondator și director general al companiei Apple Computer.

11 John Markoff, „The Passion of Steve Jobs”, The New York Times: Bits, The New York Times Company, 15 ianuarie 2008, accesat la 12 noiembrie 2019.

12 Vezi Caleb Crain, „Why We Don't Read, Revisited”, The New Yorker: Cultural Comment, Condé Nast, 14 iunie 2018, accesat la 19 noiembrie 2019; Thomas Whittington, „How Many Books Does the Average Person Read?” iris: Blog, irisreading.com, 7 octombrie 2016, accesat la 19 noiembrie 2019; „Time Spent Reading”, Public Life: Humanistic Skills and Practices, American Academy of Arts \& Sciences, humanitiesindicators.com, august 2019, accesat la 19 noiembrie 2019; Marius Chivu, „Cît, cum și ce citesc românii”, apărut în Dilema veche, nr. 474, 14-20 martie 2013, Feedbook, Adevărul Holding, accesat la 19 noiembrie 2019; Iulia Sandu, „Românii, codași la citit Cât timp alocă lecturii?" HOT Stuff, noizz.ro, 17 septembrie 2018, accesat la 19 noiembrie 2019; Știrileprotv.ro, „Motivul pentru care românii nu citesc. Editurile dau vina pe școală”, Stiri: Cultura, Stirileprotv.ro, 30 mai 2019, accesat la 19 noiembrie 2019.

${ }^{13}$ Pentru ceea ce este un critic, vezi Northrop Frye, "The Responsibilities of the Critic", $M L N$, vol. 91, no. 5, 1976, pp. 797-813. JSTOR, jstor.org, accesat la 30 noiembrie 2019; F.0. Matthiessen, "The Responsibilities of the Critic", în Bernard S. Oldsey și Arthur 0. Lewis, Jr., editori, Visions and Revisions in Modern American Literary Criticism, New York, Dutton, 1962; Michael Evans, „The Role of a Critic”, Work: Careers: Restaurant \& Food Service Jobs, Chron.com. 27 martie 2019, accesat la 30 noiembrie 2019; Roland Greene, „The Social Role of the Critic”, Arcade: Blogs, Stanford University, 2010, accesat la 30 noiembrie 2019; Daniel Mendelsohn, „A Critic's Manifesto”, The New Yorker: PageTurner, Condé Nast, 28 august 2012, accesat la 30 noiembrie 2019. 
descifra sensurile textelor lor, fie (în același timp) și-au considerat propriile creații suficient de bine alcătuite pentru a face superfluu orice text așa-zis explicativ, este o provocare teribilă. Dacă dorința cea mai intensă a unui interpret este aceea de a comunica, înlesnind accesul la text al celui mai puțin versat în tehnicile subtile ale disecției literare metodice și riguroase, și, prin aceasta, de a aduce totodată un anumit gen de omagiu, animat și onest, talentului deosebit al autorului selectat, teama, concomitentă, cea mai acerbă a respectivului interpret, adesea extrem de specializat, este aceea de a nu leza integritatea însăși a ceea ce prețuiește mai mult: textul literar primar, opera de artă; autorul însuși, chiar. Cu atât mai intensă este această dorință și cu atât mai acerbă, această teamă la cel care întreprinde pentru prima dată un excurs critic de mare întindere.

Studiind intens opera și feluritele tipuri de detalii adiacente constituirii acesteia, de la aspectele tehnice la istoriile crude, autorul studiului critic ajunge să pătrundă într-un univers al scriitorului în care foarte puțini au, în fapt, acces; conștiința acestui lucru conduce la nașterea unui extrem de acut simț al responsabilității față de operă, dar și, nu în mai mică măsură, faţă de autorul acesteia. Proiecția, chiar dacă imposibilă în planul realității, a unei întâlniri cu autorul, a unei discuții față în față cu acesta, are forța de a paraliza atunci când apare temerea că săpăturile, iscodirile docte ar putea să ducă spre teritorii nevizate - evitate, ocolite, chiar, cu grijă - de către autor, spre zone sensibile ale personalităţii, alcătuirii generale sau operei sale, spre ipoteze supărătoare, spre concluzii care ar nemulțumi prin caracterul lor intransigent și frust. Ultimul lucru pe care cercetătorul dorește să îl realizeze este, într-adevăr, incomodarea - că aceasta este neintenţionată, este, în acest stadiu, irelevant - tocmai a celui căruia, prețuindu-l pentru meritele sale întru totul exemplare, îi dedică în exclusivitate timpul și energia sa.

Mai este, însă, vorba despre perceperea clară, inechivocă a mesajului transmis în și prin opera autorului studiat. Dacă această reflectare a operei în studiul critic și a intenției autorului în conștiința cercetătorului nu se realizează, întregul demers, oricât de migălos, și indiferent de cât de multe resurse ar fi implicat realizarea acestuia, se vădește complet inutil. Dacă, dimpotrivă, prin și în urma studierii operei, cercetătorul ajunge să

14 Despre cercetare și cercetători, vezi Jonathan O'Donnell, „What is research?" The Research Whisperer, WordPress.com, 18 September 2012, accesat la 2 decembrie 2019; „Understanding Research”, Toolbox: Understanding Development, Education \& Training Unit (ETU) for Democracy \& Development, accesat la 2 decembrie 2019; „Understanding Research", Evidence-Based Education, The Wing Institute, 2019, accesat la 2 decembrie 2019; „Research in Essays and Reports. Glossary of Grammatical and Rhetorical Terms", Humanities: English, ThoughtCo, accesat la 2 decembrie 2019; „What do researchers do?" Impact \& Evaluation, Vitae Careers Research and Advisory Centre (CRAC) Limited, 2019, accesat la 2 decembrie 2019; Dnyaneshwar Vithalrao Mule, „What are the characteristics of good researcher?", ResearchGate: Question, researchgate.net, 4 aprilie 2016, accesat la 2 decembrie 2019. 
recunoască teza, miza, dorința autorului ca pe ale sale proprii, în același timp rămânând integru și distinct ca individualitate, dar și ca exemplar al rasei sale, cercetarea se validează; însă, concomitent, lucrurile se complică și mai mult. În cazul specific al operei a doi autori de teatru modern de prim rang, care avertizează asupra arbitrariului funest al universului, dilema care se ridică este în ce măsură, prin ce tip de atribuiri, determinări, procedee și clasificări se justifică săvârșirea unui studiu dedicat celor care au izbutit să consolideze convingerea iniţială, proprie cercetătorului, că, în lumea care ni se oferă spre locuire, nu există speranță, că ființa umană este o creatură eminamente solitară și menită să se zbată zadarnic spre a se găsi și a se înţelege pe sine.

Un răspuns extrem de simplu, desigur, ar fi acela că încercarea (în sensul clasic, cu trimitere la eroii legendari, al cuvântului: truda, munca) interpretului nu este cu nimic mai puțin justificată decât efortul scriitorului analizat de a înfățișa finitudinea copleșitoare a omului și rezistenţa universului la strădaniile acestuia de a fi fericit, de a găsi un sens fie și numai uneia dintre acțiunile sale. Mai puțin facilă, însă, o altă soluție la dilema ivită prin pătrunderea înțelesului care condiționează opera de artă supusă investigației este acceptarea canonului interpretării ca fiind adiacent operei examinate. Altfel spus, un test impus sieși, prin care cercetătorul caută să confere operei o câtime de justificare în plus - un apendice a cărui existență este motivată de ideea că, prin cantitatea sporită și dispersarea/ disiparea controlată a noului tot, ceea ce a existat inițial se întregește (enunț formulat cu toată modestia!), iar, prin valențele noi astfel dobândite, își exercită funcțiile - de diseminare, instruire și delectare (aceasta din urmă, inevitabilă, prin componenta estetică, sau desăvârșirea formală, a textului) - cu o farâmă de eficacitate suplimentară. Textul critic, prin urmare, se constituie în acest caz într-un adjuvant cu funcție de promovare și semnalizare.

Fiecare pas al acestei migăloase încercări, de a contura și evidenția ceea ce, în teatrul absurd ${ }^{15}$, este iluzoriu deși, în mod aparent, expus atât de natural, cu mijloace și prin modalități atât de înșelător de nesofisticate, este făcut cu sârguința celui care se reclamă din tradiţia lectorului evlavios, pentru care creatorul iscusit și talentat își are locul în panteonul oricărei civilizații înaintate, pentru care arta este sinonimă cu darul absolut, dar și cu sacrificiul suprem.

Demersul este, astfel, împotriva tuturor obstacolelor, dus la bun sfârșit pentru că, dacă textele dramaturgului absurd descriu lumi din care nu vrei să faci parte, care nu lasă speranță, piesele unor reprezentanți de marcă -

\footnotetext{
${ }^{15}$ Vezi, ca punct de pornire, lucrări de referință precum Nicolae Balotă, Lupta cu absurdul, Bucureşti, Editura Univers, 1971 sau Martin Esslin, The Theatre of the Absurd, 3rd edition, Vintage, 2004.
} 
Ionescu, Beckett, Arrabal... - reușesc, totuși, cumva - prin execuția impecabilă, prin felul în care stau mărturie a dorinței autorilor de a nu ceda nici ei în faţa ororilor și disperării și de a continua să creeze -, să impulsioneze, scoțând cititorul/spectatorul din deznădejdea în care îl aruncă iniţial și în care îl mențin pe durata desfășurării scenelor și tablourilor. Scos în mod paradoxal la liman tocmai de către textul care îi confirmă rolul suprem al întâmplării și al haosului în univers, omul, în final, se regăsește pe sine puternic - practic, indestructibil.

O confirmare a acestei imense puteri de a îndura a omului, a capacităţii sale extraordinare de a se regenera, o regăsim, peste ani, la un alt vizionar mult încercat: autorul, interpretul și călugărul budist Leonard Cohen, care mărturisește chiar pe scenă - deși, nu într-un spectacol de teatru:

„De atunci am luat mult Prozac, Paxil, Wellbutrin, Effexor, Ritalin, Focalin... De asemenea, am studiat profund filosofiile religiilor. Dar veselia a ieșit mereu învingătoare" $[\text { tr.n. }]^{16}$.

Din asemenea surse își trage cercetătorul de față puterea.

\section{Bibliografie generală}

„Ballpoint Pen History - Who Invented Ballpoint Pen?” History of Pencils: Pen and Pencils History, HistoryOfPencils.com, 2019, accesat la 8 decembrie 2019.

Balotă, Nicolae, Lupta cu absurdul, Bucureşti, Editura Univers, 1971.

Bendig, Martin, „Biography”, Eugène Ionesco, ionesco.de, 2019, accesat la 27 noiembrie 2019.

Chivu, Marius, „Cît, cum şi ce citesc românii”, apărut în Dilema veche, nr. 474, 14-20 martie 2013, Feedbook, Adevărul Holding, accesat la 19 noiembrie 2019.

Coelho, Paul, Al cincilea munte, traducere din portugheză de Carmen Vasilescu, București, Humanits, 2010.

Computer Hope, „When was the first computer invented?” Computer Hope: History Q\&A, Computer Hope, 2 august 2019, accesat la 8 decembrie 2019.

16 „Leonard Cohen - The Future - Live in London”, YouTube, 28 august 2009, accesat la 12 septembrie 2010. De asemenea, Joseph O'Connor, „«I was 60 years old, just a kid with a crazy dream»", în Culture, The Irish Times, 12 noiembrie 2016, accesat la 27 noiembrie 2019. 
Crain, Caleb, „Why We Don't Read, Revisited”, The New Yorker: Cultural Comment, Condé Nast, 14 iunie 2018, accesat la 19 noiembrie 2019.

Esslin, Martin, The Theatre of the Absurd, 3rd edition, Vintage, 2004.

Evans, Michael, „The Role of a Critic”, Work: Careers: Restaurant \& Food Service Jobs, Chron.com. 27 martie 2019, accesat la 30 noiembrie 2019.

„Fountain Pen - History of Fountain Pens”, History of Pencils: Pen and Pencils History, HistoryOfPencils.com, 2019, accesat la 8 decembrie 2019.

Frye, Northrop, “The Responsibilities of the Critic", $M L N$, vol. 91, no. 5, 1976, pp. 797-813. JSTOR, jstor.org, accesat la 30 noiembrie 2019.

Greene, Roland, „The Social Role of the Critic”, Arcade: Blogs, Stanford University, 2010, accesat la 30 noiembrie 2019.

History.com Editors, „Printing Press”, HISTORY, A\&E Television Networks, 7 mai 2018, actualizat la 10 octombrie 2019, accesat la 8 decembrie 2019.

Krishnan Unni, „Fountain Pen: Science and History”, Amrita Vishwa Vidyapeetham, amrita.edu, 22 octombrie 2018, accesat la 8 decembrie 2019.

„Leonard Cohen - The Future - Live in London”, YouTube, 28 august 2009, accesat la 12 septembrie 2010.

Markoff, John, „The Passion of Steve Jobs”, The New York Times: Bits, The New York Times Company, 15 ianuarie 2008, accesat la 12 noiembrie 2019.

Matthiessen, F.0., „The Responsibilities of the Critic”, în Bernard S. Oldsey și Arthur 0. Lewis, Jr., editori, Visions and Revisions in Modern American Literary Criticism, New York, Dutton, 1962.

Mendelsohn, Daniel, „A Critic's Manifesto”, The New Yorker: Page-Turner, Condé Nast, 28 august 2012, accesat la 30 noiembrie 2019.

Mule, Dnyaneshwar Vithalrao, „What are the characteristics of good researcher?” ResearchGate: Question, researchgate.net, 4 aprilie 2016, accesat la 2 decembrie 2019.

O'Connor, Joseph, „«I was 60 years old, just a kid with a crazy dream»”, Culture, The Irish Times, 12 noiembrie 2016, accesat la 27 noiembrie 2019.

O'Donnell, Jonathan, „What is research?” The Research Whisperer, WordPress.com, 18 September 2012, accesat la 2 decembrie 2019.

„Research in Essays and Reports. Glossary of Grammatical and Rhetorical Terms”, Humanities: English, ThoughtCo, accesat la 2 decembrie 2019.

Sandu, Iulia, „Românii, codași la citit - Cât timp alocă lecturii?” HOT Stuff, noizz.ro, 17 septembrie 2018, accesat la 19 noiembrie 2019.

Strong, Benjamin, „Samuel Beckett: A Short Biography”, samuel beckett society: Biography, The Samuel Beckett Society, accesat la 27 noiembrie 2019.

Știrileprotv.ro, ,Motivul pentru care românii nu citesc. Editurile dau vina pe şcoală”, Știri: Cultura, Stirileprotv.ro, 30 mai 2019, accesat la 19 noiembrie 2019. 
The Editors of Encyclopaedia Britannica, „Typewriter”, Encyclopcedia Britannica, Encyclopædia Britannica, inc., 13 februarie 2018, revizuit și adus la zi de Robert Lewis, accesat la 8 decembrie 2019.

„Time Spent Reading”, Public Life: Humanistic Skills and Practices, American Academy of Arts \& Sciences, humanitiesindicators.com, august 2019, accesat la 19 noiembrie 2019.

„Understanding Research”, Evidence-Based Education, The Wing Institute, 2019, accesat la 2 decembrie 2019.

„Understanding Research”, Toolbox: Understanding Development, Education \&

Training Unit (ETU) for Democracy \& Development, accesat la 2 decembrie 2019.

„What do researchers do?" Impact \& evaluation, Vitae Careers Research and Advisory Centre (CRAC) Limited, 2019, accesat la 2 decembrie 2019.

Whittington, Thomas, „How Many Books Does the Average Person Read?” iris: Blog, irisreading.com, 7 octombrie 2016, accesat la 19 noiembrie 2019. 